\title{
El general Ángel Flores y el apoyo de los católicos para su campaña a la presidencia de la República en 1924
}

\author{
The general Ángel Flores and the support of Catholics for his \\ campaign for the presidency of the Republic in 1924
}

Juan González Morfín ${ }^{1}$

Fecha de recepción: 9 de mayo de 2020

Fecha de aceptación: 31 de julio de 2020 


\section{Resumen}

En 1923, un grupo de católicos promovió la candidatura a la presidencia de la República del general Ángel Flores, revolucionario, con un papel destacado en la política regional y amigo del presidente Álvaro Obregón. Su contendiente era el general Plutarco Elías Calles. A pesar de una campaña intermitente y de escasa penetración, Flores consiguió una gran cantidad de votos y, después de las elecciones, durante algún tiempo se mantuvo viva la posibilidad de un levantamiento armado por parte de sus seguidores. En este artículo se busca profundizar en las motivaciones que condujeron a los católicos a apoyar esta candidatura y mostrar cómo algunos de sus líderes no eran ajenos a la opción de levantarse en armas luego de las elecciones.

Palabras clave: revolucionarios, política, Iglesia católica, levantamiento armado, campaña electoral.

\section{Abstract}

In 1923, a group of Catholics promoted the candidacy for the presidency of the Republic of general Ángel Flores, a revolutionary, with a prominent role in regional politics and a friend of president Álvaro Obregón. His contender was general Plutarco Elías Calles. Despite an intermittent and low-penetration campaign, Flores garnered a large number of votes and, after the elections, the possibility of an armed uprising by his followers was kept alive for some time. This article seeks to delve into the motivations that led Catholics to support this candidacy and show how some of their leaders were not strangers to the option to rise up in arms after the elections.

Keywords: revolutionaries, politics, Catholic Church, armed uprising, electoral campaign. 


\section{Introducción}

$\mathrm{U}$

n personaje poco tratado por la historiografía nacional, quizá incluso también por la regional (Hernández, 1981; Verdugo, 2005), es el general Ángel Flores. Oriundo de San Pedro, municipio de Navolato, apenas a unos cuantos kilómetros de Culiacán, Sinaloa. Mas no por haber sido hasta ahora poco tratado, deja de ser un personaje de relieve.

Nacido en 1883, trabajó como marinero en diversos vapores de matrícula mexicana y extranjera. Luego en Mazatlán se contrató como estibador y, en 1910, se levantó en armas con Francisco I. Madero. Terminada la lucha contra Porfirio Díaz, regresó a Mazatlán a sus antiguas tareas. En 1913 nuevamente tomó las armas contra Victoriano Huerta y en las tropas constitucionalistas fue ascendiendo en el escalafón militar hasta llegar al grado de general. Obtuvo renombradas victorias en Topolobampo, Mazatlán y, sobre todo, en el combate de Hermosillo, donde derrotó a las fuerzas del general Francisco Villa. En 1916, regresó a Sinaloa donde fungió unos meses como gobernador interino. En 1920 secundó el levantamiento de los sonorenses y, al asumir la presidencia Álvaro Obregón, fue designado Jefe de la Primera División del Noroeste, para encargarse de las operaciones militares en Baja California, Sonora, Sinaloa y Nayarit. Fue gobernador nuevamente de su estado en el periodo 1920-1924, aunque no terminó su mandato para competir en las elecciones de ese último año. Favoreció la recuperación económica no solo de su estado, sino de toda la región noroeste (INEHRM, 2014, pp. 376-378). Se opuso al reparto agrario y las buenas relaciones que mantenía con Obregón le permitieron actuar en esto con una gran libertad. ${ }^{2}$ Cuenta Juan de Dios Bojórquez que cuando el general Múgica preguntó a Obregón quién había sido, a su juicio, el mejor general de la Revolución, este, sin titubear, afirmó: “-¡Ángel Flores!” (Bórquez, 1963, p. 35).

De su campaña presidencial se han ocupado diversos trabajos de investigación (José, 1983; 1998; 2002; 2012; López, 2005), pero, más específicamente del apoyo que le dieron los católicos y de la penetración que tuvo su campaña en este sector de la población se ha hablado más bien poco.

En este artículo trataremos de profundizar en el apoyo que le dieron los católicos a Ángel Flores, junto con otros sectores conservadores, y se buscará sobre todo una aproximación a las motivaciones que llevaron a los políticos católicos a postularlo como candidato a la presidencia.

\section{La participación de los católicos en política en los años anteriores}

En mayo de 1911 se fundó el Partido Católico Nacional, una asociación política oficialmente católica que buscaba influir en los destinos del país a través de los cauces institucionales. En las elecciones presidenciales de noviembre del mismo año, los católicos apoyaron a Francisco I. Madero en una fórmula que llevaba como candidato a la vicepresidencia a Francisco León de la Barra. Posteriormente participarían

2- Un tema a profundizar que no será tocado en este artículo es el de la renuencia de Flores a implementar en el noroeste la incipiente reforma agraria, pues si bien es mencionado en diversos trabajos (José, 1983: 192-193; Verdugo, 2005: 33-36), en ninguno de ellos constituye el tema principal. 
con candidatos y fórmulas propias en las elecciones federales y estatales convirtiéndose en una fuerza nada despreciable, incluso temida por las agrupaciones políticas de corte liberal. ${ }^{3}$

Sin tener fuerza suficiente para obstaculizar las propuestas de Madero, sin embargo, sistemáticamente votaron en contra de estas una vez que se había instalado la XXVI legislatura en septiembre de $1912 .{ }^{4}$ No obstante esta oposición persistente a las iniciativas presidenciales, su desgracia se originó del apoyo que algunos de sus miembros prestaron al gobierno de Victoriano Huerta. ${ }^{5}$

Por más que muchos de sus afiliados manifestaron de mil maneras su repudio al gobierno golpista de Huerta -e, incluso, el presidente del Partido Católico, Gabriel Fernández Somellera fue perseguido, encarcelado y, finalmente, desterrado, así como Enrique Zepeda, director del diario católico La Nación, que terminó clausurado y muchos otros católicos que también sufrieron represalias-, no obstante, a la vista de los constitucionalistas, los católicos habían sido parte del movimiento que derrocó a Madero y, por lo mismo, dignos de todo tipo de represalias.

De esa forma, el Partido Católico quedó proscrito a partir de 1914. En la Constitución de 1917 quedó expresamente prohibido que se hiciera alusión a las religiones dentro del nombre y de los idearios de cualquier partido político y los católicos, que durante casi cinco años no habían hecho acto de presencia en la política nacional, no volvieron a la arena política sino hasta 1920, que reaparecieron con el nombre de Partido Nacional Republicano.

La duración de este partido fue efímera; surgió intempestivamente para presentar como candidato contra el general Álvaro Obregón a un viejo maderista, ni siquiera de filiación católica, Alfredo Robles Domínguez, quien obtuvo una cantidad de votos irrisoria. ${ }^{6}$ Este partido quedaría virtualmente disuelto después de las elecciones, aunque consiguió ganar la gubernatura de Aguascalientes con Rafael Arellano Valle, quien pudo gobernar el estado sin muchos sobresaltos en el periodo para el que había sido elegido 1920-1924.

Aunque el gobierno del general Álvaro Obregón no quiso aplicar las leyes constitucionales vigentes desde 1917 que limitaban en algunos campos la acción de la Iglesia y, en otros como el de la educación, llanamente la excluían, sin embargo, algunas agresiones que no tuvieron mayores consecuencias -como las bombas que explotaron en los arzobispados de México y Guadalajara, así como la parcialidad del gobierno a favor de los presuntos agresores de los católicos en algunos zafarranchos que se llevaron a cabo en Morelia y Guadalajara-, condujeron a los líderes políticos católicos a denunciar un estado de verdadera persecución y a buscar organizarse para cambiar ese estado de cosas. Especialmente cuando se enteraron de que el candidato oficial sería el general Plutarco Elías Calles, con quien habían tenido los católicos amargos desencuentros desde que había sido gobernador de Sonora. ${ }^{7}$

No teniendo un caudillo que los representara y conociendo que el general Ángel Flores era un opositor declarado de Calles y que gozaba de gran prestigio entre los agricultores por haber impedido en

3- En las elecciones para diputados federales de 1912, el PCN reclamó el triunfo de 76 de sus candidatos; sin embargo, únicamente se le reconocieron 29 (González, 2012: 388). En las elecciones locales, ganó el estado de Jalisco y estuvo muy cerca de ganar Guanajuato. Uno de sus dirigentes, Rafael Ceniceros y Villarreal, gobernó como interino el estado de Zacatecas.

4- Los primeros diez meses de su gobierno, Madero coexistió con un congreso elegido durante el gobierno del general Díaz. Cuando ya se hubo instalado la XXVI legislatura, tuvo un apoyo mínimo de esta, incluso por parte de los diputados de su partido y más todavía del pequeño grupo de diputados católicos (véanse Palavicini, 1998: 402-408; Serrano, 1994: 182-190).

5- Especialmente Eduardo Tamariz y Francisco Elguero, aunque no nada más ellos (O’Dogherty, 2001: 211).

6- 47,442 votos, contra más de un millón cien mil de Álvaro Obregón.

7- Siendo gobernador interino de Sonora expulsó a todo el clero católico en 1916 (Krauze, 1987, p. 32). 
Sinaloa una reforma agraria de carácter anárquico que hubiera desfavorecido la productividad, lo buscaron para plantearle que fuera su candidato a la presidencia.

Los católicos acudieron al general a través del Lic. Miguel Palomar y Vizcarra, quien buscó convencerlo de que el respaldo de los católicos sería decisivo para su triunfo sobre Calles:

Como militar constitucionalista Ángel Flores tenía sus reservas hacia la religión y el clero católico, y Palomar lo sabía, pero recurrió a él porque para las aspiraciones de los dirigentes católicos "importaba muy poco que fueran o no católicos los gobernantes", siempre y cuando reconocieran las libertades de la Iglesia y les permitieran a ellos desenvolverse como una fuerza social y política. El general Flores aceptó diciendo que de llegar a la presidencia buscaría la apertura de un diálogo entre el Episcopado y su gobierno, que condujera a la recuperación de las libertades perdidas por la Iglesia, pero sin salirse del marco jurídico constitucional. (Lira, 2010, p. 74)

Sin duda una de las características que llevaron a los políticos católicos a pensar en el general había sido una afirmación que él había hecho públicamente unos años atrás y que había trascendido: que si Calles era el candidato a la presidencia, él, Flores, impediría por los medios que fueran oportunos que este llegara a ocupar el cargo presidencial.

De esto había sido enterado incluso el general Calles cuando era Secretario de Gobernación con el presidente Obregón en una carta que le envió, ya en campaña, uno de sus seguidores:

Hemos sido informados ... de que el C. Gral. Ángel Flores, Gobernador Constitucional de aquella Entidad, trata de organizar Cuerpos Rurales a pretexto de mantener el orden y la estabilidad de su Gobierno ... . [Es sabido] que ya en 1921 había manifestado su decisión de oponerse por medios extremos a la postulación del C. General Don Plutarco Elías Calles sin hacerse la salvedad de que si era o no impuesto, sino que dijo lo impediría por el solo hecho de ser "bolsheviki".

\section{Cartas de presentación del general Ángel Flores}

Entre algunos sectores del catolicismo social existía un verdadero temor de que los bolcheviques llegaran al poder (Barbosa, 2014 pp. 55-81). Algunas actuaciones de Calles, ciertamente anticlericales, pero no necesariamente bolcheviques, así como su discurso muchas veces favorable a los postulados socialistas, habían servido para convencer a este sector de católicos que lo peor que podría pasar era la llegada de Calles al poder. Tenían que organizarse y buscar quién le hiciera frente. La primera carta, indiscutible, había sido el ex presidente Adolfo de la Huerta, de pensamiento liberal, pero claramente moderado y que ya había dado muestras claras de mantener un espíritu conciliatorio por encima de los mandatos

8- Ocurso enviado por Emiliano C. García al Secretario de Gobernación Plutarco Elías Calles, 31 de diciembre de 1923, Fideicomiso de Archivos Plutarco Elías Calles - Fernando Torreblanca, Archivo Plutarco Elías Calles (APEC), expediente 63 , inventario 2235 , f. 2 r. 
constitucionales de la carta magna del 17. Como era un hecho que su movimiento podía fracasar y, de hecho, así fue, los católicos necesitaban una segunda opción y acudieron por ello al militar sinaloense. ${ }^{9}$

En un folleto repartido por la Liga Política Nacional, asociación hacia la cual había evolucionado el Partido Nacional Revolucionario, se mencionaban las características que hacían de Ángel Flores el candidato idóneo para representar a todos los mexicanos: ${ }^{10}$

Salido de las clases humildes del pueblo, forjado en la fatiga y el dolor, templado en los afanes de una existencia trabajosa, el General Flores es un self made man, un hombre que todo lo debe a sí mismo (5).

No es el General Ángel Flores, por ser General, por revolucionario, por temerario, por victorioso, el que merezca el voto de la República. Lo merece, sí, porque muchas otras condiciones lo distinguen, y de aquí que se mencione su vida en la contienda armada: mientras muchos contribuían a que se prolongara la lucha, huyendo de las acciones decisivas, el General Flores batía resueltamente al enemigo (10).

Sin preferencias ni protecciones para gremios, para facciones, para particulares simpatías, el General Flores se manifestó como el verdadero gobernante del pueblo: que sirve a todos los intereses, que garantiza todos los derechos, que impulsa todos los justos y avanzados ideales, que es un positivo servidor de la sociedad que tiene derecho a la vida en todas sus manifestaciones y en todas sus energías (14).

Es notorio e innegable, no solo en el Estado de Sinaloa sino en la grande zona que sintió de cualquier manera el influjo del General Flores, que su característica invariable es la honradez; que sus facultades administrativas le realzan notablemente; que su espíritu de justicia le ha hecho iniciar leyes en bien de la agricultura, del comercio, la industria, todas, en fin, las actividades en lícita pugna, y sobre todo mantener tal equilibrio entre las tendencias y las necesidades de elementos que se juzgan antagónicos: el Capital y el Trabajo, que los factores de unos y otros se consideran favorecidos y tienen a manos abiertas el aplauso que aprueba y que premia, para la acción del gobernante (14-15).

También se menciona cómo un estado recibido en bancarrota fue convertido por él en uno de los estados con más superávit en la federación y el único al corriente en los créditos adquiridos por otras administraciones. Por todo ello, concluía el documento que presentaba a Ángel Flores como candidato de la Liga Política Nacional:

El ciudadano Ángel Flores es modesto, de costumbres sencillas, afable y franco, refractario a los vicios, honrado a carta cabal, enemigo del servilismo, enérgico en cuanto las situaciones lo

9- La campaña militar que apoyaría a Adolfo de la Huerta y terminaría fracasando, comenzó a gestarse desde el año 1922 y, también desde ese mismo año, el presidente Álvaro Obregón y su grupo, incluido Calles, habían comenzado a mover sus piezas para contrarrestarla (Plasencia, 1998, pp. 23-280).

10- Breves apuntes del C. General Ángel Flores. Candidato a la Presidencia de la República en el Periodo Constitucional 1924-1928, folleto impreso, octubre de 1923, Archivo Histórico del Centro de Estudios de Historia de México Carso (CEHM), fondo DCXXI, legajo 955, carpeta 10, documento 1. 
demandan, defensor de los desvalidos, protector decidido del trabajo, sostenedor del orden, baluarte de la justicia y de las ideas avanzadas, y guía sus actos por la divisa inmortal: "EL REPETO AL DERECHO AJENO...” (15).

En el mismo folleto, al final, venía el programa de la Liga Política Nacional, que era sustancialmente el mismo que había postulado el Partido Nacional Republicano en la elección presidencial de cuatro años antes y, en su momento, el Partido Católico Nacional, es decir, una armonización de la llamada doctrina social de la Iglesia con algunos postulados revolucionarios:

\section{Gobierno Nacional.}

II. Respeto a las Instituciones de la Familia y de la Propiedad.

III. Solución del Problema Agrario sobre bases de Justicia y Equidad. Creación de la Pequeña Propiedad accesible a todos.

IV. Armonía entre el Capital y el Trabajo. Legislación protectora del Trabajo.

V. Protección al Comercio y a la Industria. Desarrollo de la Marina Nacional. Garantías a la Inversión del Capital.

VI. Moralización de la Administración Pública y del Mecanismo Judicial. Creación del Servicio Civil, garantizando la estabilidad y recompensas del empleo público haciendo efectivas las Leyes de responsabilidad para los funcionarios públicos.

VII. Dignificación del Ejército.

VIII. Sufragio Efectivo y No Reelección.

IX. Libertad para todos: de conciencia, de enseñanza, de asociación y de trabajo.

X. Igualdad para todos ante la Ley (contraportada).

Aunque el folleto no ostentaba firma alguna y es probable que la redacción haya sido revisada por varios, de todas maneras acusaba la autoría de Miguel Palomar y Vizcarra, quien no desaprovechaba oportunidad para esgrimir como solución de fondo para los problemas nacionales la armonización entre el trabajo y el capital. Por otra parte, era precisamente Palomar, quien reconocía haber sido juarista y que algunos postulados del prócer liberal eran compatibles con la mentalidad católica (Olivera, 1970, pp. 9-10).

\section{Algunos católicos que lo apoyaron: el caso de Capistrán Garza y Palomar y Vizcarra}

En el largo camino de Calles a la presidencia durante el proceso electoral 1923-1924, muchos católicos participaron primeramente al lado del Lic. Adolfo de la Huerta, incluso algunos de ellos se levantaron en armas secundando el levantamiento militar que intentó llevarlo al poder (Blanco, 2002, pp. 154-171). Ya en estos momentos, al mismo tiempo que a través de la Liga Política Nacional apoyaba la candidatura del general Flores, un personaje muchas veces citado y que ha sido hasta ahora poco estudiado, René Capistrán Garza, animaba a los católicos de distintas agrupaciones católicas a organizarse para participar en la lucha armada: 
La persecución religiosa se desatará inevitablemente y los que nos hemos destacado en la oposición ... cuando llegue Calles al poder iremos inmediatamente al paredón. Por otra parte, es muy poco artístico que nos dejemos sorprender de esa manera brutal; pero aún podemos salvarnos, si de una vez por todas hacemos frente virilmente a los acontecimientos. (Blanco, 2002, p. 157)

Capistrán Garza era un líder católico altamente politizado. ${ }^{11}$ En diversas ocasiones pisó la cárcel por sus ideas políticas (Capistrán, 1958). Fue reconocido por ser un orador que incendiaba a las masas. ${ }^{12} \mathrm{Al}$ iniciar la campaña a favor de Ángel Flores con la Liga Política Nacional, seguía siendo el presidente de la Acción Católica de la Juventud Mexicana (A.C.J.M.), por lo que el secretario de la Delegación apostólica, Mons. Tito Crespi, le llamó fuertemente la atención haciéndole ver que no podía mezclar la religión con la política. Él replicó argumentando que el arzobispo de México le había dicho que estando la situación como estaba, era oportuno que la A.C.J.M. entrara en una fase de actividad política (Valvo, 2016, p. 142). En su fogosidad, reparaba poco en las consecuencias que atraería un levantamiento armado y, en los diferentes foros en que interactuaba, buscaba dejar abierta siempre la puerta al recurso de las armas. Así lo asienta Barquín y Ruiz en un documento en que pretende narrar la historia de la A.C.J.M. Ante pregunta directa sobre si los medios que se usarían en la lucha por rescatar los derechos de los católicos serían únicamente los legales, respondió que "los medios serán los constitucionales y los exigidos por el bien común. O sea, también el ejercicio del derecho a la rebeldía bélica”. ${ }^{13}$ Blanco Ribera, sin criticarla, atribuye esta impetuosidad a su escasa formación intelectual: "si René hubiera sido más erudito, más filosófico y más teorizante, habría sido menos líder, menos agitador de conciencias y tal vez hubiera tenido menor calidad como paladín de nuestra causa" (Blanco, 2002, p. 187).

Muy diferente en cuanto a su manera de actuar estaba el licenciado Miguel Palomar y Vizcarra, ${ }^{14}$ a quien se puede considerar el intelectual de los católicos combativos, pues prefirió mantenerse siempre detrás del telón en las organizaciones que asesoraba. Escribió numerosos folletos y tratados y pronunció incontables discursos. Por aquellas épocas, invirtió gran parte de su tiempo en la formación intelectual de los jóvenes católicos (Lira, 2010, pp. 83-96; Hernández, 2014, pp. 173-188). Era más partidario que Capistrán Garza de luchar por un cambio a través de las vías legales, pero tampoco descartaba el recurso a lo que él llamaba la "defensa armada". Estaba convencido de que los católicos no podían quedarse en vivir la caridad, sino que tenían que pasar a la acción cívica para cambiar las estructuras sociales del país. ${ }^{15}$ A diferencia de Capistrán, no esperaba nada bueno de Adolfo de la Huerta si este llegara al poder. Así lo afirmaba en una carta de

11- René Capistrán Garza (1898-1974): Nació en Tampico, fue abogado de la Universidad Nacional de México, líder católico en los años veinte, después un crítico destemplado de la jerarquía católica, jefe cristero en los primeros meses de la Cristiada, la mayor parte de su vida la dedicó al periodismo.

12- Por sus dotes oratorias, fue llamado por la prensa norteamericana "el Mussolini Mexicano" (Blanco, 2002, p. 188).

13- Historia de la A.C.J.M., documento mecanografiado firmado por Andrés Barquín y Ruiz, CEHM, fondo CLXXXVI, carpeta 46, documento 4782, ff. 18-19.

14- Miguel Palomar y Vizcarra (1880-1968): Nacido en Guadalajara se graduó ahí mismo de abogado. Participó desde muy joven en los congresos y actividades que se organizaban para impulsar la acción social de los católicos. Fue uno de los fundadores del Partido Católico Nacional, con el que ganó una diputación en su estado natal durante el gobierno de Madero. Su vida la invirtió en la propagación de la doctrina social de la Iglesia.

15- Se pueden escuchar estas ideas en una interesante entrevista que le hizo Alicia Olivero Sedano en los años sesenta: https://con-temporanea.inah.gob.mx/post_gutenberg/alicia_olivera_num9 
marzo de 1924 escrita a un sacerdote amigo suyo, residente en Roma: "Se dice que entre los Pío Latinos que son mexicanos hay una simpatía muy grande en favor de D. Adolfo de la Huerta: no la merece ese cínico, y hay quienes estiman que es peor que el otro, pues Calles no es hipócrita" ${ }^{16}$

En cualquier caso, tanto Palomar como Capistrán se encontraban en el grupo de los católicos intransigentes, es decir, de los que no se resignaban ante los obstáculos, cualesquiera que fueran, para buscar implantar en el país lo que ellos denominaban "el orden social cristiano". En Ángel Flores habían visto un instrumento idóneo, aunque no fuera católico, para luchar de cara a conseguir este objetivo. Palomar y Vizcarra, por la vía del voto; Capistrán Garza sin descartar el recurso a las armas, quizá incluso con la esperanza de que se dieran las circunstancias para llegar a esa situación.

\section{Una campaña tormentosa}

Calles había propiamente comenzado su campaña electoral en septiembre de 1923, con las necesarias interrupciones por el levantamiento delahuertista. Sin embargo, no había dejado de estar presente en los diarios, incluso desde meses antes de iniciarla, y contaba con el apoyo decidido de algunos de ellos, principalmente de El Demócrata. Por su parte, Ángel Flores apenas sí había dado muestras de interés por participar: en agosto de 1923 pidió su baja en el ejército, en octubre aceptó que la Liga Política Nacional comenzara a promover su candidatura, ya en abril de 1924 anunció que iniciaría su campaña el 1 de mayo y no fue sino hasta el 2 de mayo que lanzó un manifiesto a la nación explicando sus objetivos de campaña, entre los que estaban armonizar la interpretación y la aplicación de las leyes constitucionales, promover la prosperidad de los pequeños propietarios, cumplir con las asignaciones ejidales sin lesionar los legítimos intereses y, algo muy interesante en lo que no habían reparado los candidatos de otros partidos: dar amplias garantías a las empresas y personas extranjeras, de cualquier nacionalidad, para trabajar por el bien del país, siempre que aquello fuera sin perjuicio para los mexicanos (José, 2002, p. 92).

Por increíble que parezca con un candidato que mostraba tan poco entusiasmo en iniciar su campaña, sin embargo, las adhesiones a Flores se multiplicaron en el norte, centro y occidente del país. El entusiasmo de los católicos, por un lado, y de los terratenientes, clases medias y pequeños propietarios, fue nuevamente desbordante. Proliferaron los partidos locales de filiación florista y la respuesta de sus contrincantes fue sembrar el terror.

Flores, quien poco antes del relanzamiento de su campaña había sufrido un amago de atentado con una bomba que explotó en el hotel donde se hospedaba (José, 2002, pp. 91-92), acudió al presidente Obregón el 27 de mayo para solicitarle amplias garantías para él y sus seguidores. Al día siguiente, los diarios informaban que "el Primer Mandatario le reiteró que su gobierno le dará amplias garantías en su propaganda política. Le dijo que denunciara inmediatamente cualquiera irregularidad, atentado o abuso de que fuera víctima él o alguno de sus partidarios". ${ }^{17}$

No obstante las ofrecidas garantías, pocos días después la prensa reportaba que al pasar el tren en que viajaba el general Ángel Flores por San Juan del Río, el convoy fue tiroteado por un numeroso grupo

16- Miguel Palomar y Vizcarra a David G. Ramírez, México, 9 de marzo de 1924, CEHM, fondo CLXXXVI, carpeta 1, documento 73, f. 13.

17- El Informador, 28 de mayo de 1924: 1. 
de agraristas, que portaban bandera rojinegra. Del ataque resultaron ocho muertos y once heridos. Y después de llegar el candidato Flores a Querétaro, y al ir por la calle de Cuauhtémoc, nuevamente fue atacado por los agraristas. En este nuevo ataque, resultaron más muertos y heridos, contándose entre los de gravedad al exgobernador Ramírez Luque. ${ }^{18}$

Apenas un par de días después, en su arribo a Aguascalientes, de donde proseguiría su campaña por Guadalajara y algunos puntos de Los Altos de Jalisco, un nuevo ataque se verificó en contra de su comitiva. Los titulares de la prensa daban cuenta de una "nueva refriega entre callistas y floristas" acaecida en Aguascalientes, donde "a la llegada del general Ángel Flores se trabó un fuerte tiroteo en el cual resultaron muertos numerosos espectadores". ${ }^{19}$ En esta ocasión el escándalo fue mayor pues algunos de los caídos en la trifulca eran menores de edad, según lo hacía notar El Informador: "Hasta los momentos de recibirse el mensaje, se sabe que entre los muertos habidos en el encuentro entre callistas y floristas se cuentan dos señoritas y cuatro niños, un anciano y muchas otras personas". Nuevamente el presidente Obregón habría de intervenir o, al menos, de simular que lo hacía: según constata la noticia: "El C. Presidente de la República, inmediatamente que tuvo conocimiento de los sucesos en Aguascalientes, giró órdenes expresas a las autoridades militares por donde vaya pasando el General Flores en su propaganda política, para que eviten atentados contra su persona y la comitiva que lo acompaña". ${ }^{20}$

Los atentados obligaron a Flores a suspender su campaña por Jalisco, que se esperaba apoteósica, así lo informaba la prensa el día 15 de junio. ${ }^{21}$ De ahí pasó a Durango y el 22 de junio tuvo nuevamente que interrumpir su campaña y regresar a su estado, ahora para atender a su padre que había enfermado de gravedad. En Sinaloa pasó los últimos días previos a la elección casi sin haber hecho campaña.

Por su parte, Calles cerraba su campaña a tambor batiente, después de una última gira ininterrumpida de cuarenta días por el centro, norte y occidente del país, tocando muchos de los puntos donde se esperaba una votación más copiosa para Ángel Flores (José, 2012, p. 336).

Los católicos, a pesar de todo, estaban optimistas. La sola posibilidad de votar en contra de Calles había animado a una gran parte del electorado. Sin embargo, los dirigentes de la Liga Política Nacional en más de un momento habían pensado en retirar su apoyo a Flores. Así lo contaba Palomar y Vizcarra por carta a un amigo sacerdote en esos momentos radicado en Roma:

Flores no ha estado muy cortés ni muy acertado con nosotros los católicos, pues significó que Capistrán y yo podríamos ser una rémora para su campaña. La Liga le declaró que estaba en un error y que era el momento de acabar con preocupaciones sectarias. Capistrán y yo esperamos que venga el General a México (probablemente llega esta semana) y le exigiremos en buenos términos que modifique su juicio, y si no lo hace y no nos da garantías y seguridades de que ha de respetar las libertades que fueron consignadas en el programa de la Liga, le abandonaremos. Ya escribiré a Ud. sobre el particular. ${ }^{22}$

18- El Informador, 11 de junio de 1924: 1.

19- El Informador, 13 de junio de 1924: 1.

20- El Informador, 13 de junio de 1924: 1.

21- El Informador, 15 de junio de 1924: 1.

22- Miguel Palomar y Vizcarra a David G. Ramírez, México, 9 de marzo de 1924, CEHM, fondo CLXXXVI, carpeta 1, documento 73, ff. 12-13. 
Muchos años después, en una entrevista concedida en 1964, Miguel Palomar y Vizcarra refería que habían llevado a cabo la campaña electoral en "condiciones miserables" (Wilkie, 2001, p. 189). No obstante la falta de recursos, en el occidente y en algunos puntos del norte del país, la Liga Política Nacional, como en su momento lo había hecho el Partido Católico, se sirvió de los establecimientos parroquiales para realizar sus reuniones de propaganda y para conseguir adeptos (Guízar, 1976, pp. 36-37; O’Dogherty, 2001, p. 111).

Así las cosas, llegaron las elecciones el domingo 6 de julio. Durante el periodo de Obregón se había reformado la ley electoral en dos ocasiones. En ambos casos, para dar un mayor control sobre la elección a quien organizaba las elecciones, esto es, al gobernante en turno. Sobre estas modificaciones a la ley electoral, subraya Georgette José que "lo más grave de las reformas obregonistas, tanto la de 1921 como, sobre todo, la de 1923, fue que a través de los artículos 41 y 42, de manera anticonstitucional, se anuló el secreto del voto, en 1923 se minimizó la participación de los representantes de los partidos y se abrió la puerta para la comisión legal del fraude" (1998, p. 49).

Ese día, la afluencia de votantes fue superior a la que se esperaba. En algunos lugares del occidente del país hubo mesas electorales en las que sufragaron todos los empadronados. ${ }^{23}$ En diferentes poblaciones al final de la jornada electoral se dieron a conocer resultados aplastantes a favor de la candidatura de Ángel Flores. José Guízar Oceguera narra que en Cotija la victoria fue tal que por la tarde de ese domingo se organizó una marcha triunfal y una verbena popular (Guízar, 1976, p. 37). Sin embargo, los cómputos oficiales se darían en los días sucesivos según fueran sesionando las juntas electorales de cada estado.

$\mathrm{Al}$ día siguiente, tanto los floristas como los callistas se autoproclamaron vencedores. Los floristas no sin protestar por un sinnúmero de irregularidades cometidas sobre todo en el occidente del país, donde no faltaron zafarranchos, arrestos e, incluso, muertos, también durante los días sucesivos. ${ }^{24}$

En el distrito de Zamora, Michoacán, el general José Álvarez, oriundo del lugar y, en ese momento, hombre de confianza de Calles, informaba a su jefe el día 11 de julio como había conseguido que concluyera la votación: 10,081 votos por el general Calles, 1,483 por el general Ángel Flores. Presumía que justamente en ese distrito, considerado baluarte del florismo, se hubiera propinado una derrota tan notable a los reaccionarios. ${ }^{25}$

Lo mismo ocurrió en el estado de Jalisco, donde la gente se había volcado a votar por Flores. Los datos oficiales publicados el día 10 de julio, según informó la prensa al día siguiente, le daban a Plutarco Elías Calles una diferencia de diez a uno sobre su contrincante. ${ }^{26}$

Los floristas no se esperaron a que se diera a conocer oficialmente el cómputo final, pues conforme avanzaban los recuentos locales, se iba afianzando la distancia entre los votos que se les estaban reconociendo y los del candidato oficial. Por ello, comenzaron a denunciar un fraude generalizado y anunciaron

23- A diferencia de las elecciones federales de 1911, para elegir presidente, y 1912, para diputados federales, en las que el episcopado había alentado la participación del electorado católico, en estas elecciones se abstuvo de intervenir.

24- Véanse las ediciones de El Informador de los días 7, 8, 10 y 12 de julio de 1924.

25- Información que transmite por telegrama la secretaria del general Calles, Soledad González de Anaya, a su jefe, el 11 de junio de 1924, APEC, expediente 105, legajo 2/9, inventario 2417, f. 86.

26-"Datos oficiales indican que en Jalisco el Gral. Calles obtuvo cien mil votos contra diez mil" (El Informador, 11 de julio de 1924: 1). Según los resultados oficiales publicados unos días después en los que se mencionaba la votación recibida estado por estado, Calles, en Jalisco, obtuvo 95,191 votos, mientras que Flores solamente 13,701. En Querétaro, otro de los estados supuestamente floristas, la votación oficial fue aún más dispareja: arrojó 21,324 por Calles, contra 694 de Flores. 
que impugnarían la elección ante el Procurador General y solicitarían la anulación de las elecciones, ${ }^{27}$ hecho que nunca ocurrió.

\section{Un levantamiento armado largamente planeado}

Es difícil creer que, en algún momento, tanto los católicos como los agricultores y demás grupos que apoyaron la candidatura de Ángel Flores hubieran tenido esperanzas fundadas de ganar las elecciones y de que se reconociera su triunfo. En cambio, hay algunos indicios que permiten sospechar que el acudir a un proceso electoral amañado desde antes por los cambios en la legislación electoral que favorecían la falta de transparencia, no fue sino un paso necesario para, con cierta legitimidad, convocar a un levantamiento armado. ¿No había anticipado años atrás el general Flores que si Calles era el designado para sustituir a Obregón él lo impediría a toda costa, incluso si Calles triunfaba en las elecciones?

Pero para levantarse en armas había que tener un motivo suficiente, no bastaba la animadversión a Calles, era necesario que se dieran unas elecciones como se dieron: ensangrentadas por la violencia preelectoral y salpicadas de dudas, incluso de evidencias, de una manipulación de los resultados finales.

Cabe señalar que la votación final reconocida al general Ángel Flores no fue pequeña, contra 1 340634 reconocidos a Calles, Flores obtuvo 252 599, una votación dos veces y media superior a la que se reconocería a Vasconcelos unos años después, y casi el doble de la que se concedió a Almazán en 1940. No fue sino hasta 1952, casi 30 años después, con la candidatura de Efraín González Luna en contra del Lic. Adolfo Ruiz Cortines, que un candidato de derecha obtuviera una cifra apenas mayor ${ }^{28}$ a la que se reconoció a Ángel Flores y, más desconcertante aún, no fue sino hasta 1988, con el ingeniero Manuel J. Clouthier, que un candidato de esa línea obtuviera un porcentaje superior al obtenido por Flores. ${ }^{29}$

Es por ello que el número, no pequeño, de votos reconocidos en medio de una elección tan dudosa, facilitó a los partidarios de un levantamiento armado la legitimidad mínima para convocarlo, por más que ya venía siendo preparado independientemente de cómo se realizaran las elecciones. ${ }^{30}$

Efectivamente, según menciona Georgette José, "algunos integrantes del SNA y de la Liga Política Nacional, como Ignacio Gastélum, Guillermo Pous, Moisés García y René Capistrán Garza ... desarrollaron febril actividad para conseguirlo, fijando como fecha del levantamiento el 1 de noviembre de 1924, para de esta forma impedir la transmisión pacífica del poder" (1988, p. 223).

En junio de 1924, poco antes de que Flores renunciara a hacer campaña en Guadalajara, las oficinas del SNA habían sido clausuradas por el gobierno al haber encontrado en ellas una cantidad inexplicable de armas (José, 2002, p. 94). Y, en carta de mayo de 1924 interceptada por el gobierno, un agente de Flores manifestaba que al aproximarse las elecciones, Flores estaría en Chihuahua o en alguna ciudad cercana a la frontera "donde él encontrará a todos los partidarios que ha citado ahí para ese

27-El Informador, 14 de julio de 1924: 1.

28- 285,555 votos.

29- Ángel Flores el 15.82\%; Manuel J. Clouthier el 17.07\%.

30- Sobre el número de votos reconocido a Flores, asienta Lorenzo Meyer: "esta vez el candidato oficial triunfó por un margen menos espectacular y por ello más realista que el de sus predecesores" (1985, p. 83). 
tiempo. Contamos con elementos efectivos que ya están listos en nuestro Estado, cinco aeroplanos y suficientes rifles y municiones, los cuales serán de gran valor al iniciar". ${ }^{1}$

No obstante los preparativos, que sí existieron, nunca se dio el levantamiento. Así, el 1 de noviembre de 1924, la fecha prevista, los diarios nacionales no solo no anunciaban un nuevo conato de revuelta, sino que invertían la mayor parte de sus primeras planas para hablar de la reunión del presidente electo, Plutarco Elías Calles, con el presidente norteamericano Calvin Coolidge, con quien sostuvo una larga conferencia. Solo unos días después, cerca del 20 de noviembre, comenzó a expandirse la noticia de que el general Ángel Flores se había sublevado, hecho que a la postre se comprobó que era falso.

En el archivo del general Calles se encuentran telegramas y cartas de adhesión alusivas a esta falsa alarma: "Con motivo informes sublevación Ángel Flores, Partido Revolucionario Pro-Educación protesta a Usted su franca y leal adhesión". ${ }^{32} \mathrm{O}$ este otro telegrama escrito por el general Martín Espinosa y otros tres presuntos diputados callistas por el estado de Sinaloa: "hónranos ofrecer servicios caso confírmese sublevación Ángel Flores". ${ }^{33}$ Las informaciones procedían de algunos diarios vespertinos de la Ciudad de México y fue nada menos que el presidente Álvaro Obregón quien tuvo que salir al paso para desmentirlas al mismo tiempo que "ordenó al Procurador General de la República, que sean consignados los periódicos en que haya aparecido esa noticia” ${ }^{34} \mathrm{Al}$ día siguiente, entrevistado en Mazatlán Sinaloa, el general Ángel Flores afirmaba a la prensa que desde principios de julio se encontraba retirado de la política y, por lo tanto, eran completamente falsos los rumores de que se hallaba al frente de un nuevo levantamiento. ${ }^{35}$ Aun así, el 1 de diciembre de 1924, al tiempo que el general Calles rendía su protesta como presidente, un nuevo manifiesto atribuido a Ángel Flores se fijaba en muchos lugares públicos del norte y occidente del país desconociendo el gobierno de Calles e invitando a la rebelión (Iglesias, 1998, pp. 938-940).

\section{Fin del general Ángel Flores y la nueva lucha de los católicos}

A decir verdad, todo hacía ver que el general Ángel Flores había tenido ya suficiente y que ahora lo que buscaba era un poco de paz: desilusionado del fracaso electoral, indignado por el comportamiento de Obregón que no cumplió su palabra de garantizar unas elecciones confiables y despechado con los delahuertistas, que en los últimos días de su campaña le retiraron su apoyo según se desprende de la prensa y de la correspondencia cruzada entre ellos. ${ }^{36}$ Sobre esto último, Georgette José reporta una carta

31- A. G. Perales a Frank Rogers, 21 de mayo de 1924, APEC, expediente 28, legajo 1, f. 10.

32- Rafael Jiménez a Plutarco Elías Calles, Villa de Guadalupe, S.L.P., 23 de noviembre de 1924, APEC, expediente 57, inventario 3006, legajo 1.

33- Martín Espinosa a Plutarco Elías Calles, 23 de noviembre de 1924, APEC, expediente 79, inventario 1901, legajo 1, f. 5.

34- El Informador, 23 de noviembre de 1924: 1. En el archivo personal del general Calles solamente hay una mención, no confirmada por ninguna otra fuente, de un motín armado en apoyo del general Ángel Flores en una pequeña localidad de San Luis Potosí (Rafael Jiménez a Plutarco Elías Calles, Villa de Guadalupe, S.L.P., 24 de noviembre de 1924, APEC, expediente 57, inventario 3006, legajo 1).

35- El Informador, 24 de noviembre de 1924: 1.

36- Según informó la prensa, en torno al 23 o 24 de junio el propio Adolfo De la Huerta escribió a sus seguidores para que se abstuvieran de cualquier tipo de actividad en contra del gobierno del general Obregón, así como de cualquier apoyo a la campaña de Flores. Solo se opuso a esto el ex diputado Jorge Prieto Laurens, quien en su momento había militado en la Acción Católica de la Juventud Mexicana (véase El Informador, 25 de junio de 1924: 1). 
en la que el exgobernador delahuertista de Puebla, Froylán C. Manjarrez, busca convencer a uno de sus correligionarios exponiendo las siguientes razones para no seguir a Flores:

¡No te metas en esa burrada! Nosotros no tenemos por qué avergonzarnos de haber seguido al señor De la Huerta, porque en todo caso era una escisión entre el mismo Partido Revolucionario tradicional. Habrá si tú quieres diferencia de criterio en cuanto al procedimiento, pero siempre bajo nuestros indiscutibles principios de renovación social. Pero el florismo es una claudicación absoluta, es la traición a la revolución, la reacción misma, neta y descarada. Y ni tú ni yo debemos mancharnos con eso, ya que nuestro único patrimonio dentro de la política mexicana son nuestros firmes principios revolucionarios. (José, 2002, p. 94)

Ahora ni los católicos, ni los agricultores, ni sus copiosos votantes, se preocupaban de él, a no ser para algo que, al fin de cuentas, había rehusado: levantarse en armas. Todavía en 1925, ahora paradójicamente los delahuertistas, lo invitarían a formar parte de un gran levantamiento armado. Su respuesta fue no (Verdugo, 2005, p. 43).

Habiendo tenido posibilidades reales a su paso por el poder para haberse labrado una fortuna, el caso es que sus últimos días los transcurrió entre dolores, enfermedades y carencias económicas. El general Roberto Cruz, quien combatió a Villa bajo el mando de Ángel Flores en las épocas del constitucionalismo, relata lo siguiente:

El general Flores fue nombrado comandante militar de la zona más grande que bajo su mando haya tenido algún jefe, pues se componía de los estados de Nayarit, Sinaloa, Sonora y Baja California. Una zona extensísima y muy rica. El general Flores era jefe absoluto de ese extenso territorio y él nombraba desde un gobernador hasta el último empleado. Con todas estas facultades el general Flores pudo haberse hecho millonario, pero como era un hombre a más de valiente muy honrado murió pobre y la familia no tenía con qué sepultarlo. Los amigos tuvimos que hacerlo. (Cruz, 1979, p. 186)

De esta forma, retirado y llevando una vida de austeridad y privaciones, recibió la noticia de que estaba envenenado probablemente con arsénico. Los síntomas vitales estaban disminuyendo y el médico que lo atendía no vislumbraba remedio alguno que revirtiera su muerte. Como en otras ocasiones, afrontó su destino con verdadero estoicismo. Relata su esposa: "Desde el momento en que Ángel se consideró envenenado, ordenó terminantemente a mí y a las demás personas que vivíamos a su lado que guardáramos estricto secreto". ${ }^{37}$

Los estudios que se practicaron al cadáver revelaron que efectivamente había rastros de arsénico. Las versiones que se propalaron para encontrar una explicación "razonable" fueron sobre todo dos: le habían suministrado arsénico por error al confundir el frasco de la medicina indicada; y, un poco más verosímil, durante algún tiempo había tomado para sus dolores reumáticos medicinas que contenían arsénico, por eso era lógico que se encontraran indicios en el cadáver. Ni la viuda, ni los deudos del 
fallecido quisieron dar mayor importancia al suceso y ahí quedó todo.

Menos aún se ocupó la opinión pública de otro evento lamentable que apenas sí mencionó la prensa: veinte días después de la muerte de Flores, fue asesinado en Nogales Gregorio Esparragoza, quien había sido secretario particular del general.

Por su parte, los católicos olvidados de su excandidato habían proseguido su lucha. En marzo de 1925 habían formado la Liga Nacional Defensora de la Libertad Religiosa, asociación de carácter cívico en la que, curiosamente, habían confluido la mayoría de los que habían integrado primeramente el Partido Nacional Republicano y posteriormente la Liga Política Nacional. Ahora se agrupaban bajo una bandera que les podía, debido a las estridencias de Calles, producir en el corto plazo mayores beneficios políticos: la defensa de la libertad religiosa. ${ }^{38}$ El secretario de Gobernación, licenciado Gilberto Valenzuela, desde el primer momento denunció este subterfugio al declarar a la prensa "que la agrupación que pretende formarse no es una agrupación religiosa, puesto que no tiene por objeto el hacer propaganda para obtener mayor número de adeptos de determinada secta religiosa, sino que se trata de una agrupación política, puesto que cuanto pretende es de carácter político, como que se reforme la Constitución, defender los derechos cívicos de los ciudadanos, etc." ${ }^{39}$ En breve se les vería convocar a la lucha armada en contra de la ley del general Calles que adicionó el Código Penal para sancionar las infracciones en materia de culto y religión: habían cambiado la lucha institucional por la lucha armada o, tal vez, habían encontrado las circunstancias adecuadas para el levantamiento armado que no se dio después de la derrota de Flores.

\section{Consideraciones finales}

Georgette José Valenzuela, quien ha estudiado a fondo esta época, expone esta sugerencia interesante en uno de sus escritos:

que el origen de la disputa que llevó a la rebelión cristera ya en el gobierno callista fue prefigurada a partir de la beligerancia propiciada por los discursos y las acciones no sólo del mismo Calles, sino también de sus oradores en campaña. Pareciera que los contendientes comenzaron a preparar el terreno sobre el cual habrían de medir sus fuerzas; y si en un primer momento esa lucha se planteó en términos de disputa democrática por la consecución de los votos, el terreno minado sobre el que ambas fuerzas caminaron no podía augurar otro desenlace que el que sobrevino pocos años más tarde. (2002, p. 108)

Coincidimos en lo esencial con ella: la campaña del general Ángel Flores fue, al menos en un doble sentido, el laboratorio que incubó la guerra cristera: primero, porque los católicos descartaron que la vía electoral

38- En una obra en que Palomar y Vizcarra defiende con tintes épicos la actuación cívica de los católicos en el periodo revolucionario y posrevolucionario, le da una importancia muy grande a lo conseguido por el Partido Católico Nacional y, sobre todo, al levantamiento armado de los años 1926-1929; sin embargo, la campaña presidencial de 1924 ni siquiera recibe una mención (Palomar, 1945, pp. 125-229).

39- Excélsior, 22 de marzo de 1926. Véase también documento mecanografiado firmado por Andrés Barquín y Ruiz: "Los acejotaemeros repartieron el manifiesto de la fundación de la Liga Nacional de Defensa Religiosa en todo el Distrito Federal", CEHM, fondo CLXXXVI, carpeta 1, documento 79, ff. 1-2. 
podía llevarlos a conseguir sus objetivos; segundo, porque intentaron caminos equivocados para conseguir un levantamiento armado, caminos que buscarían no volver a repetir. Sin embargo, falta un elemento por considerar en lo que sería en breve tiempo el detonante del nuevo conflicto: el encono alimentado por Calles contra el elemento católico por el apoyo que dieron primeramente a De la Huerta y luego a Flores.

En efecto, en un libro publicado en 1926 por Antonio Uroz, uno de partidarios de Calles cuya pluma muchas veces le servía de altavoz, una vez que se habían generalizado las medidas restrictivas en contra de la Iglesia católica, el autor las justificaba en un epígrafe cuyo título era “¿Quién ha tirado la primera piedra?” y la explicación que daba era la siguiente:

En ningún país del mundo se ha hecho oposición tan tenaz y enconada al aspirante a regir los destinos de una nación, como en nuestra patria se le hizo al General Calles, cuando se presentó a la Presidencia de la República.

No escatimaron los clericales y sus adláteres medio alguno para hacer impopular y desprestigiar al hoy Presidente de México ... .

Era sencillamente ridículo continuar tolerando infracciones escandalosas a la Constitución ... .

$\mathrm{Si}$ a esto agregamos el que los mismos burladores de las leyes, los clérigos, estaban luchando constantemente y por malas artes con el fin de destruirlas -aunque de hecho no se les obligaba a su cumplimiento- preciso es convenir en que el General Calles ha estado justiciero al exigir rotundamente el exacto cumplimiento de la Constitución .... .

Y si a esto todavía añadimos que la provocación ha partido del mismo clero, toda persona sensata y desapasionada convendrá en que asiste la razón al Presidente de México (1926, pp. 89-93).

Al tenor de lo que afirma Uroz, la oposición decidida de los católicos en las elecciones de 1924 habían determinado que el general Calles urgiera la aplicación, hasta ese momento en suspenso, de los artículos más anticlericales de la Constitución.

Podemos concluir proponiendo que el general Ángel Flores fue un buen candidato para los católicos, porque les ayudó a conseguir una gran cantidad de votos y les permitió organizarse en torno a un proyecto esencialmente anticallista, que era lo que en ese momento perseguían. Sin embargo, a pesar de que esa gran cantidad de sufragios obtenida fue en buena parte gracias a que la campaña florista se sirvió de las estructuras que habían venido tejiendo los católicos, no se puede afirmar que los católicos hayan sido el mejor aliado político para un general revolucionario, como lo era Ángel Flores, pues su alianza con estos lo alejó para siempre de la amistad con Obregón y, sobre todo, le privó en esa coyuntura política del apoyo de los delahuertistas y quizá también de otros revolucionarios.

Finalmente, en relación con los resultados oficiales de la votación, es difícil pensar que si se hubiera respetado la voluntad del electorado Ángel Flores hubiera ganado las elecciones, sobre todo por lo pobre de su campaña; no obstante, se puede presumir sin el riesgo de ser temerarios que la diferencia de votos con el general Calles fue mucho menor que la reconocida. 


\section{Referencias}

\section{Archivos:}

-Archivo Histórico del Centro de Estudios de Historia de México Carso (CEHM).

-Fideicomiso de Archivos Plutarco Elías Calles - Fernando Torreblanca, Archivo Plutarco Elías Calles (APEC).

\section{Periódicos:}

-El Informador, Guadalajara.

-Excélsior, Ciudad de México.

\section{Bibliografía:}

Barbosa Guzmán, F. (2014). El miedo católico a los bolcheviques (México, años veinte, siglo XX). En A. Regalado (Coord.), Violencias y miedos. Una reflexión desde la historia, el cine y las migraciones contemporáneas (pp. 55-81). Universidad de Guadalajara - CULagos.

Blanco Ribera, C. (2002). Mi contribución a la Epopeya Cristera. Una época terrible y tormentosa. APC. Capistrán Garza, R. (1958). Andanzas de un periodista y otros ensayos. Atisbos.

Cruz, R. (1979). Roberto Cruz en la Revolución Mexicana. Diana.

González, J. (2012). Entre la espada y la pared: el Partido Católico Nacional en la época de Huerta. Anuario de Historia de la Iglesia, 21, 387-399.

Hernández Tyler, A. (1981). Gobernador culiacanense. Ángel Flores. Presagios, 5, (83), 25-27.

Hernández Vicencio, T. (2014). Revolución y Constitución. Pensamiento y acción política de Miguel Palomar y Vizcarra, Historia y Grafía (42), 159-192.

Iglesias González, R. (1998). Planes políticos, proclamas, manifiestos y otros documentos de la Independencia al México moderno, 1812-1940. UNAM - IIJ.

INEHRM. (2014). Diccionario de generales de la Revolución I: A-L. INEHRM.

José Valenzuela, G. (1983). La oposición menor a la candidatura presidencial de Calles. Estudios de Historia Moderna y Contemporánea de México, 9, 171-204.

José Valenzuela, G. (1988). Ángel Flores el candidato de la reacción. En C. Martínez Assad (Coord.), Estadistas, caciques y caudillos (pp. 205-241). UNAM - IIS.

José Valenzuela, G. (1998). La campaña presidencial de 1923-1924 en México. INEHRM.

José Valenzuela, G. (2002). Campaña, rebelión y elecciones presidenciales de 1923 a 1924 en México, Estudios de Historia Moderna y Contemporánea de México, 23, 55-111.

José Valenzuela, G. (2012). La primera campaña presidencial posrevolucionaria exitosa: 1923-1924. En G. José Valenzuela (Coord.). Candidatos, campañas y elecciones presidenciales en México. De la República Restaurada al México de la alternancia: 1867-2006 (pp. 291-349). UNAM - IIS. 
Krauze, E. (1987). Plutarco E. Calles, Reformador desde el origen. Fondo de Cultura Económica.

Lira Soria, E. (2010). Miguel Palomar y Vizcarra. Católico militante (1880-1968). DEHAG - Dirección de Cultura del Ayuntamiento de Guadalajara.

López González, A. (2005). Ángel Flores, candidato a la presidencia de la República en 1924. UAS.

Meyer, L. (1985). La Revolución mexicana y sus elecciones presidenciales. 1911-1940. En P. González Casanova (Coord.). Las elecciones en México: evolución y perspectivas (pp. 69-100). Siglo XXI.

O’Dogherty Madrazo, L. (2001). De urnas y sotanas. El Partido Católico Nacional en Jalisco. Conaculta. Olivera, A. (1970). Miguel Palomar y Vizcarra y su interpretación del conflicto religioso de 1926. INAH.

Palavicini, F. (1998). La XXVI legislatura. En E. De la Torre Villar, (Ed.), Lecturas Mexicanas III (pp. 395408). UNAM - IIH.

Palomar y Vizcarra, M. (1945). El caso ejemplar mexicano. Hacia la cumbre de la cristiandad. Rex-Mex.

Plasencia de la Parra, E. (1998). Personajes y escenarios de la rebelión delahuertista. 1923-1924. UNAM - IIH.

Serrano Ortega, J. (1994). Reconstrucción de un enfrentamiento: el Partido Católico Nacional, Francisco I. Madero y los maderistas renovadores (julio de 1911-febrero de 1913). Relaciones Estudios de Historia y Sociedad, 15 (58), 167-196. https://biblat.unam.mx/en/revista/relaciones-colmich-zamora/ articulo/reconstruccion-de-un-enfrentamiento-el-partido-catolico-nacional-francisco-i-maderoy-los-maderistas-renovadores-julio-de-1911-febrero-de-1913

Uroz, A. (1926). La cuestión religiosa en México. Editado por el autor. Valvo, P. (2016). Pio XI e la Cristiada. Fede, guerra e diplomazia in Messico (1926-1929). Morcelliana. Verdugo López, M. (2005). Ángel Flores. El caudillo de San Pedro. Difocur.

Wilkie, J. y Monzón, E. (2001). Frente a la Revolución mexicana. 17 protagonistas de la etapa constructiva. Entrevistas de historia oral. Volumen II: Ideólogos. UAM. 

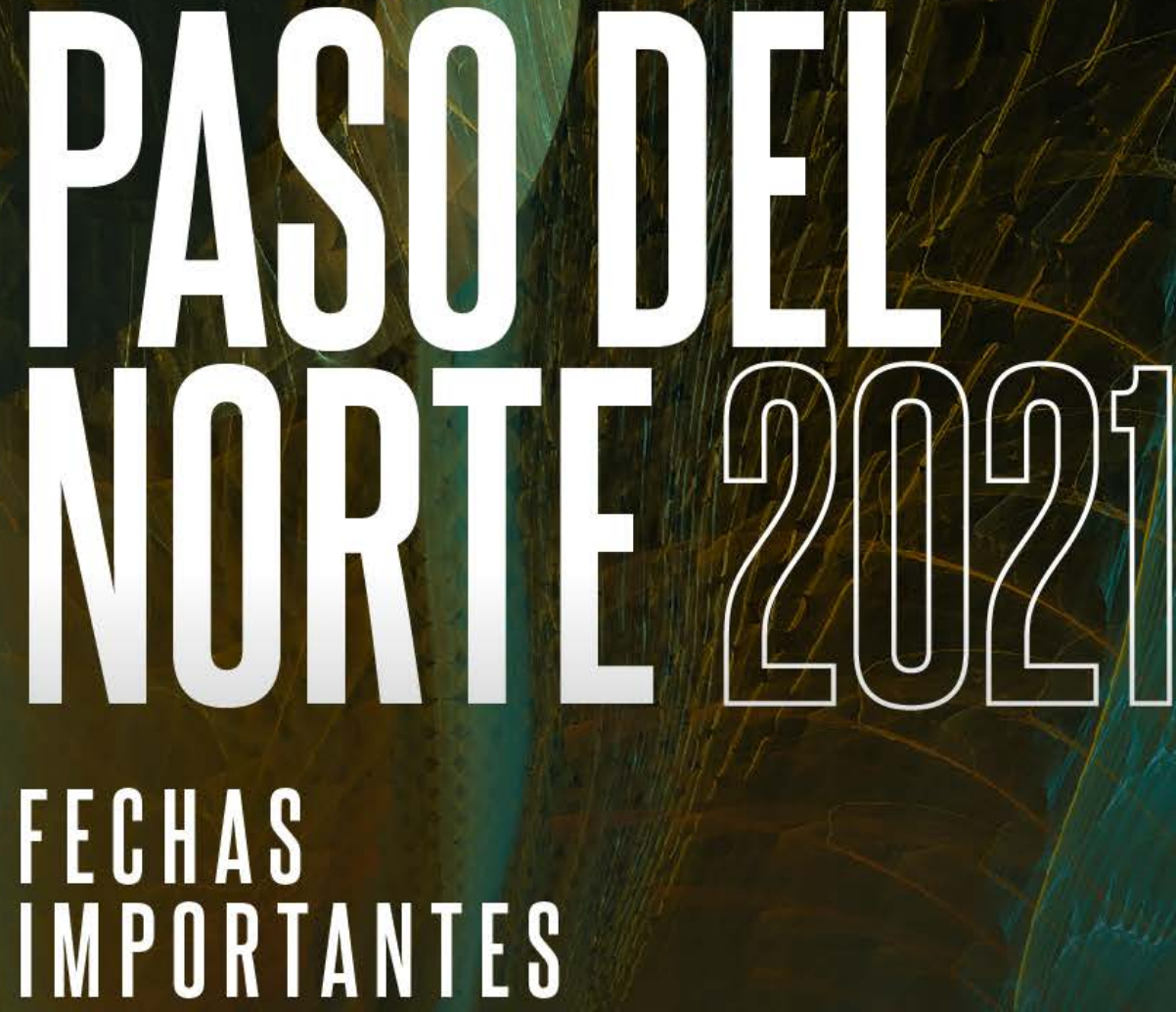

Recepción de trabajo

Del 15 de febrero al 7 de junio

Publicación de propuestas aceptadas 30 de julio

\begin{tabular}{ll}
\hline Fecha límite envío ponencias in extenso & $\mathbf{3 0}$ de septiembre \\
\hline Fecha límite de inscripción para ponentes & $\mathbf{8}$ de octubre \\
\hline Publicación del programa del Congreso & $\mathbf{2 2}$ de octubre \\
\hline Realización del Congreso & del $\mathbf{8}$ al $\mathbf{1 1}$ de noviembre \\
\hline Fecha límite para trámite de constancias & $\mathbf{3 0}$ de noviembre
\end{tabular}

Fecha límite para trámite de constancias

30 de noviembre

Registro de trabajos:

http://info.uacj.mx/congresocs2021 